\title{
SENTIDOS DO LETRAMENTO: A ESCRITA NO EVENTO VESTIBULAR
}

\author{
Victoria Wilson da Costa Coelho \\ (Universidade do Estado do Rio de Janeiro)
}

RESUMO

0 objetivo do artigo é refletir sobre práticas de letramento explícitas ou subjacentes em um evento de letramento como o vestibular tendo como objeto de estudo as redações produzidas nesse evento. Pretende-se compreender a cultura escrita escolarizada ou o letramento escolar em sua ponta, no fim do Ensino Médio, com base na teoria da enunciação de Bakhtin. Apesar das ações pedagógicas escolares voltadas para a aprendizagem da escrita elaborada (argumentativa) em razão dos exames vestibulares e do ENEM, sabemos o quanto os resultados ainda são bastante insatisfatórios em termos das práticas de letramento escolar o que merece ainda reflexão a respeito. Vale ressaltar que se entende a escrita (na/da escola) como um conjunto de práticas sociais mais do que um conjunto de habilidades.

PALAVRAS-CHAVE: práticas de letramento - evento de letramento - linguagem escrita

\section{Introdução}

0 título desse artigo remete à investigação que vem sendo desenvolvida sobre diferentes modos de ser letrado, seja em contexto acadêmico, seja no âmbito de produções escritas para o evento vestibular (WILSON, 2012, 2015). Os resultados dessas reflexões convergem para pontos que põem em relevo modos de dizer e fazer (Matencio, 2006) implicados em diferentes produções escritas e suas ações pedagógicas. 
Sentidos do letramento é um modo de olhar, observar e analisar produções escritas - redações do vestibular UERJ/2011 -, sob a perspectiva discursiva, de orientação dialógica bakhtiniana. Para esse fim, recorremos às concepções de "palavra de autoridade e palavra internamente persuasiva" (BAKHTIN, 1993). De acordo com o material analisado, é possível observar como as redações expressam modos (ou modelos) culturais de utilização do(s) letramento(s) associados ao letramento escolar. São práticas de letramento, na concepção de Barton (2000), que representam os modos ou meios como cada grupo se apropria dos usos do(s) letramento(s) em cada evento de letramento.

Os modos de apropriação do letramento são o foco deste trabalho tendo em vista o evento de letramento - vestibular - e as práticas de letramento esperadas, explícitas ou implícitas nesse evento. Como os candidatos se apropriam da língua escrita escolar e como se mostram como aprendizes são eixos de nossa indagação, sem perder de vista a dimensão político-social do letramento, ideia de que "a apropriação vai além da escrita e afeta subjetivamente os alunos" (GOULART, 2014, p. 40).

Os resultados têm nos mostrado duas tendências em termos do que se poderia chamar de letramento escolar: uma tendência homogeneizante / idealizante dos usos da escrita - convergindo para o modelo autônomo de letramento (STREET, 2014); uma outra cujas práticas apontam para usos mais diversificados da língua escrita, mais autorais. Tais tendências não são nem dicotômicas, nem excludentes: revelam o trabalho produzido na escola e reafirmam o que alguns pesquisadores já vêm pontuando: a língua escrita é heterogênea e plural (CORRÊA, 2004), e a aprendizagem de linguagens especializadas se estabelece na dinâmica e na pluralidade dos contextos sociais e dos eventos de letramento, condicionadas pelo modo como a leitura e a escrita são exploradas nesses contextos específicos - (no caso a escola). A escola, em seu esforço homogeneizador, tem sustentado determinados usos e padrões linguísticos, porém o modo como cada indivíduo se "apodera" da língua, na escola ou em outros espaços, revela também certas singularidades. Será que podemos definir um uso escolar da língua, ou mesmo falarmos em padrões de usos escolares da língua portuguesa?

Enfim, abordar os usos escolares da escrita para compreendêlos como processos inerentes à escola (ROCKWELL, 1985; SOARES, 2003) e suas implicações pedagógicas em termos da internalização 
de linguagens e saberes pelos alunos podem nos ajudar a dar sentido também às nossas próprias reflexões e práticas e pedagógicas.

\section{Os pressupostos e a confluência teórica}

0 fenômeno do letramento implica muitas discussões que estão além desse trabalho. Mas, existe uma tendência forte em situá-lo dentro dos "Novos Estudos do Letramento" (Street, 2003) com o intuito de retomar os conceitos de modelo autônomo e modelo ideológico, especialmente esse último modelo e, ainda, seguindo a orientação do mesmo autor, tratar das práticas e eventos de letramento, objetivando responder a algumas indagações por ele colocadas (STREET, 2010).

Trata-se de questões de natureza conceitual e metodológica, tais como: "devo descrever esse evento de letramento?"; “como devo descrevê-lo?”; “quais são seus componentes?” (STREET, 2010, p. 38). E para dar cabo da descrição de modo a tentar responder às questões postas, o autor se pergunta: “(...) mas onde vai dar isso? Quais são seus padrões?" (idem), referindo-se aos eventos de letramento. Por essa razão, Street lança mão do conceito de "práticas de letramento" para se referir "a aspectos que nos possibilitam começar a ver padrões nesses eventos e situar conjuntos de eventos de forma a dar a eles um padrão" (idem).

Portanto, as noções de práticas e eventos de letramento serão caras para nós, pois partimos do pressuposto de que o vestibular é um evento de letramento, ancorado em práticas de letramento escolar. São essas práticas de letramento escolar que nos possibilitarão observar e, em seguida, interpretar os padrões de comportamento linguístico que possam evidenciar tais práticas no interior do evento vestibular.

Os modelos autônomo e ideológico fornecem subsídios para a compreensão de que as práticas de letramento escolar e os eventos a elas vinculados vivem na tensão entre a dissociação do letramento da vida cultural, do contexto e da vivência e a sua dimensão política. Acreditamos que essa dimensão caminha em duas direções: no reforço dos valores institucionais de raiz escolar, tais como currículo, estratégias pedagógicas, investimentos financeiros e a sua contraparte. Trata-se de uma visão mais crítica, elaborada e consciente quanto ao letramento das pessoas, pois estas podem estar envolvidas [com o letramento] em uma forma e não em outra, "suas identidades podem 
ser diferentes, suas habilidades podem ser diferentes, seus envolvimentos em relações sociais podem ser diferentes" (idem, p. 37).

As práticas de letramento escolar, que reproduzem uma "concepção endêmica do letramento” (STREET, 1995, 2014; SOARES, 2003), acabam por encobrir ou neutralizar "a fonte ideológica daquilo que de fato são construções sociais, frequentemente associadas a ideias sobre lógica, ordem, mentalidade científica e assim por diante" (STREET, 2014). E são essas que acabam por moldar a linguagem ou a cultura escrita escolarizada, institucionalizando um modelo particular de letramento ou, nas palavras de Street (2014), "pedagogização do letramento" - . Nesse caso, a escola autonomiza "as atividades de leitura e de escrita em relação a suas circunstâncias e usos sociais, criando seus próprios e peculiares eventos e suas próprias e peculiares práticas de letramento" (SOARES, 2003, p.107), como se essas fossem apartadas de todo o contexto social fora de seus muros.

E quais as relações então entre as práticas de letramento escolar com o evento vestibular, considerando-se os modelos e as práticas supracitados? Primeiramente, a ideia de que "aprender a escrita somente tem sentido se implicar a inclusão das pessoas no mundo da escrita, ampliando sua inserção política e participação social" (GOULART, 2014, p.37). Para isso, faz-se necessário trabalhar a língua / a escrita como "atribuição de sentido, significado", sem negligenciar o pluringuismo social (BAKHTIN, 1993). Em seguida, considerar que os usos escolares da escrita ocorrem sempre na tensão entre o diálogo e a resposta ativa, ou seja, entre os discursos sociais a que os alunos estão expostos e as suas respostas a esses discursos, sem esquecer de que a escola, como um espaço bem demarcado, deve ser entendida não como entidade abstrata e sim como um lugar cheio de vida:

"los eventos comunicativos no se dan vacíos de significados socioculturales: cada hablante o lectoescritor trae a los eventos comunicativos su visión del mundo, del lenguaje, de la historia, y de los otros participantes. Desde su perspectiva el contexto es la intersección entre la dinámica de la interacción y los procesos sociales, históricos, económicos y culturales relevantes (GUMPERZ, 1984, 1986, citado por KALMAN, 2003, p.5).

Portanto, é na tensão (ou dissimulação) entre uma tendência monovocal, equivalente à força da "palavra de autoridade", enraizada 
na tradição e nos valores de instituições reguladoras, e uma tendência plurivocal, no sentido da "palavra internamente persuasiva", ambas de orientação bakhtiniana (1993), que observaremos a língua utilizada nas redações de vestibular. Se há padrões, o que mostram e o que significam em termos de um letramento escolar? E como esses padrões escondem ou manifestam abertamente outras práticas de letramento?

\section{Metodologia}

\subsection{0 caminho trilhado}

0 material de análise dessa pesquisa é constituído por 40 redações de vestibular elaboradas por candidatos à vaga na Universidade do Estado do Rio de Janeiro. 0 vestibular dessa universidade envolve outras instituições que se submetem ao mesmo esquema das provas, mas que não serão aqui contempladas.

A análise, de natureza qualitativa, parte dos domínios conceituais bakhtinianos, de orientação dialógica, com apoio dos Novos Estudos do Letramento, para compreender a escrita elaborada como prática social - processo e produto em sua dimensão "política" -. A partir dessa dimensão procuramos observar no retrato de uma escrita escolarizada - a redação de vestibular - aspectos de inclusão e participação social nos termos propostos por Goulart (2014, citada).

Os procedimentos de análise seguiram o modelo de Kalman (2003), com algumas adaptações, divididos em: (i) "aspectos observáveis" para a observação de padrões de conduta dos textos (da(s) língua(s) utilizada(s)), isto é, os modos de apropriação de enunciados alheios (tornando-os próprios) tendo em vista o outro: a banca examinadora; o evento do vestibular e as expectativas geradas por esse evento mais o imaginário sobre a escrita; (ii) "aspectos interpretáveis", a articulação de princípios e conceitos bakhtinianos para a reflexão sobre as práticas de letramento existentes / encontradas.

A interpretação do material tomou como referência a dupla orientação com foco: (i) na força da "palavra de autoridade" sobre a "palavra internamente persuasiva", com enunciados que replicam a coletânea da prova ou aderem à proposta da redação; (ii) na diluição da força da "palavra de autoridade" em direção à "palavra internamente persuasiva", com enunciados que funcionam como contrapalavras às ideias apresentadas na prova. 


\subsection{0 que podemos dizer/saber dos candidatos}

De acordo com o questionário elaborado e disponível no site da universidade, tem-se acesso às informações dos candidatos referentes a sexo, faixa etária dos candidatos, tipo de vaga, escolaridade (conclusão do ensino médio; média de leitura por ano; quantidade de livros em casa), aspectos socioeconômicos em geral: renda familiar; moradia, veículos por família; presença de computador e número de livros em casa. Os resultados mostram que os candidatos são jovens (em sua maioria mulheres: 57,13\%), com idade entre 18-20 anos, com educação sistemática, em escola particular, no turno da manhã (59,00\%). Têm acessibilidade à leitura e à escrita fora da escola (materiais impressos, internet; eventos culturais) 68,66\% têm até 50 livros em casa contra 31,34\% com mais de 50 livros, com exceção dos didáticos, com uma média de leitura de 5 livros por ano também excetuando-se os didáticos. Grande parte já fez cursos pré-vestibulares (uma média de 50\%); 70,84\% já fizeram uso de programas e provas de vestibulares anteriores; 63,35\% fizeram cursos de língua estrangeira fora da escola e 89,91\% têm computadores em casa. 0 nível de escolaridade dos pais varia entre ensino médio e ensino superior, sendo esta porcentagem maior entre as mulheres. A renda mensal bruta é de até 5 salários mínimos. A maior parte dos jovens nunca trabalhou $(67,85 \%)$ e $85,32 \%$ moram com a família em residências próprias com mais de quatro dependências contando com um a dois ou mais de dois veículos por família.

0 que se pode concluir, a grosso modo, a partir das respostas a esse questionário? A infraestrutura física e socioeconômica (sobretudo das vagas não reservadas a negros, índios e alunos de escola pública) não constitui empecilho para o acesso à e a disponibilidade para a participação em eventos de língua escrita e qualquer situação simbólica e cultural que envolva atividades relacionadas ao ler e escrever. Casa, escola, cursos e acessibilidade a bens simbólicos estão garantidos, assim como livros e computadores e aprendizagem de língua estrangeira. Deduz-se que a maioria desses candidatos pertence à classe média da população com facilidade de acesso a práticas letradas socialmente valorizadas e não somente a práticas de letramento escolar.

Kalman (2003, p.8), argumenta, porém, que "la presencia física de materiales impresos no es suficiente para diseminar la cultura es- 
crita." Em trabalho sobre gêneros discursivos e a escola, Modro argumenta que:

0 acesso a práticas sociais que envolvem os gêneros discursivos primários e secundários envolvem, também, aspectos ligados à participação social, à interação com o outro, às questões de disponibilidade dos textos, aos Sujeitos e às condições sociais para o uso de instrumentos semióticos, como parte de processos de internalização e apropriação da linguagem (MODRO, 2011, p.135-6)

Ainda que o trabalho não esteja voltado para a avaliação da qualidade dos textos em termos do que a escola não faz ou o que deveria fazer, não há como não detectar certa uniformidade no /do tratamento linguístico - seja na escolha vocabular, seja na construção de períodos e organização discursivo-textual - ou até mesmo uma sofisticação exagerada e artificial do estilo como se assim o candidato pudesse estar à altura (das expectativas) da banca. Tais usos seriam índices de que a escola ainda reproduz o modelo autônomo de letramento?

\section{Procurando respostas}

A Prova de Língua Portuguesa Instrumental com Redação tem uma peculiaridade, pois vem acompanhada de cinco questões discursivas sobre usos linguísticos, com textos que remetem ao tema da redação, formando uma espécie de coletânea de ideias. Antecedendo ainda o enunciado da questão, sempre há um texto visual ou verbo-visual ou só verbal como se fora um mote para a questão proposta. Nesta prova, foi feito um recorte de uma entrevista ao escritor português José Saramago, perguntando-lhe o que ele pensava a respeito do Twitter e da expressão em 140 caracteres, ao que o escritor respondeu:

José Saramago: Nem sequer é para mim uma tentação de neófito. Os tais 140 caracteres refletem algo que já conhecíamos: a tendência para o monossílabo como forma de comunicação. De degrau em degrau, vamos descendo até o grunhido. http:// oglobo.globo.com

Em seguida à entrevista, aparece a proposta de redação propriamente dita, solicitando ao candidato redigir um texto argumentativo, no registro padrão da língua, desenvolvendo "a sua opinião acerca da ocorrência, ou não, de um empobrecimento das 
formas atuais de comunicação entre as pessoas.”

No total das 40 redações UERJ analisadas, 50\% dos candidatos concordaram com a opinião do escritor José Saramago, seja implícita, seja explicitamente. Por quê? Por que, se são jovens que têm computador em casa e que usam, certamente, a internet em seu dia-a-dia, por meio de celulares e smartphones e para quem a linguagem da internet é familiar e apropriada às suas necessidades? Nas 50\% restantes, os candidatos dividiram-se entre discordar totalmente da opinião do escritor ou problematizar a questão, mostrando as vantagens da internet e das redes sociais.

Considerando o argumento de Venturim (2013), as práticas escolares atuam fortemente como forças centrípetas em direção ao "objeto", ou ao modelo de língua escrita, ou seja, encaminham-se na mesma direção da própria força, de fora para dentro, contrariamente à força centrífuga, que atua de dentro para fora. No entanto, na reprodução da coletânea e das palavras de José Saramago (como concordância ou discordância), o discurso citado tem como horizonte o outro: "Cada enunciado é pleno de ecos e ressonâncias de outros enunciados com outros enunciados com os quais está ligado pela identidade da esfera discursiva" (BAKHTIN, 2006, p. 297, grifo nosso). A identidade da esfera discursiva torna-se fator ou eixo preponderante para o encaminhamento da escrita do/no vestibular.

Bakhtin afirma que esse processo contínuo e constante de interação e assimilação dos enunciados é um processo "mais ou menos criador - das palavras dos outros (e não das palavras da língua)" (BAKHTIN, 2006, p. 294). Em outra passagem reafirma: "Na enunciação se expressa, portanto, a atitude do falante na sua dupla orientação: em relação àquilo de que se fala e àquele para quem se fala" (VOLOCHÍNOV e BAKHTIN, 2011, p. 28). Observemos, portanto, como os candidatos lidam com a língua escrita nas redações, considerando essa dupla orientação.

Para fins de análise, não reproduziremos as redações na íntegra. A cada fragmento ou grupo de fragmentos corresponderá uma citação de Bakhtin como forma de confirmar os usos da escrita no sentido da dupla orientação: no reforço da palavra de autoridade ou na direção da palavra internamente persuasiva.

4.1 A palavra reportada sob o peso da palavra de autoridade

(a) Ela (a palavra de autoridade) já foi reconhecida no passado. É uma palavra encontrada de antemão (BAKHTIN, 1993, p.143) 
Exemplos com foco no empobrecimento das relações entre as pessoas:

(i) As redes sociais via internet são um claro exemplo de que há, de fato, algo bem errado na sociedade. Pessoas interagem, em vários casos, com desconhecidos da mesma forma que agem com aqueles próximos de si, provocando um enfraquecimento de suas relações. Além disso, comunicar-se passa a ser algo tão automático quanto respirar, de maneira que não há necessidade de raciocinar ou pensar antes de estabelecer uma comunicação. (red.30)

(ii) Sabendo que tais recursos proporcionam muitas vantagens à sociedade, pode-se reparar os prejuízos que também os trazem; a falta de contato direto com outras pessoas, um cômodo de obter regalias sem precisar sair de casa, criando essa barreira entre as pessoas "do lado de fora", levando a sociedade cada vez mais a um mundo antissocial. (red.32)

(b) Ela (a palavra de autoridade) ressoa numa alta esfera, e não na esfera do familiar. Sua linguagem é uma linguagem especial (...). Ela pode tornar-se objeto de profanação. Aproxima-se do tabu, do nome que não se pode tomar em vão (BAKHTIN, 1993, p.143)

Exemplos com foco no empobrecimento da linguagem como se a linguagem estivesse sendo profanada, consequentemente aparecem tabus e mitos sobre a língua escrita no sentido idealizante, a saber:

(iii) Que deixem esse novo "dialeto" só para a internet, porque bonito mesmo é o português original. (red. 33)

(iv) É necessário uma postura questionadora, investigativa e crítica por cada membro da sociedade para o uso dessa linguagem inapropriada, pois a alienação provocada por esses meios geram certos vícios difíceis de escapar. Na verdade, esses meios visam à praticidade e o rompimento com o padrão da língua, onde até mesmo os caracteres são limitados. (...) Entretanto, essa nova linguagem significa um atraso social, pois rompe com a norma culta e com a riqueza cultural: a língua. (red.12)

c) (....) sua estrutura semântica é imóvel e amorfa, ou então é acabada e monossêmica, seu sentido se refere ao pé da letra, se torna rígido (BAKHTIN, 1993, p.144) 
Exemplos com foco no empobrecimento cultural/ de conhecimento: cristalização dos sentidos/ presença de lugares-comuns.

(x) A globalização faz com que as pessoas procurem por meios de comunicação cada vez mais eficientes. Essa procura por eficiência empobrece-os e acaba por deturpar livros e jornais fazendo-os aderir a essa deficiência, pois é a tendência atual. (red.10) d) $O$ discurso autoritário exige nosso reconhecimento incondicio nal e não absolutamente uma compreensão e assimilação livre em nossas próprias palavras. (...) Ela entra em nossa consciência verbal como uma massa compacta e indivisível; é preciso confirmála por inteiro ou recusá-la (BAKHTIN, 1993, p.143).

Exemplo com foco no empobrecimento das relações sociais mais amplas/ e da dimensão cultural

(xi) Por último temos a falsa amiga da sociedade moderna. As redes sociais. Bilhões de pessoas usam as redes sociais todos os dias e isso acaba gerando um grande mal para a comunicação em geral; muitos jovens adolescentes dos dias de hoje preferem ficar em casa à frente de monitores falando com pessoas que muitas vezes ele nem conhece ao invés de sair e encontrar os amigos em algum lugar. Enfim, é dever de todos, combater esses vícios ruins da sociedade moderna. 0 melhor a ser feito agora é retomar valores que se perderam ao longo do tempo para reverter o atual quadro da comunicação global. (red. 11, grifo meu) (e) As palavras autoritárias podem encarnar conteúdos diferentes (o autoritarismo como tal, a autoridade, o tradicionalismo, o universalismo, o oficialismo e outros) (BAKHTIN, 1993, p.144) Exemplos com foco na força do conhecimento da língua portuguesa (culta) e consequentemente em seu empobrecimento pelo uso do Twitter.

(xii) No entanto, ainda há uma mínima parte de apaixonados por uma boa trama [referindo-se à leitura, aos livros, em geral]; e são eles que fazem com que não seja extinto de vez o conhecimento, são eles que apreciam a língua portuguesa na forma culta e são eles também que acham que 140 caracteres não são dignos de expressar qualquer tipo de sentimen to ou opinião. São eles que devemos admirar e seguir como exemplo. (red. 3)

(v) Título: A falência múltipla da língua

(xiii) Palavras de outras línguas estão sendo, forçadamente, 
introduzidas na língua portuguesa, e isso está acontecendo com todas as línguas, até chegarmos a um ponto aonde o mundo inteiro se comunicará com a mesma língua, sem regras e for mada basicamente de consoantes. (red. 40)

4.2 A palavra reportada em direção à palavra internamente persuasiva

(a) $\dot{A}$ diferença da palavra autoritária exterior, a palavra persuasiva interior no processo de sua assimilação positiva se entrelaça estreitamente com a nossa palavra (BAKHTIN, 1993, p. 145)

Exemplo com ênfase na valorização da internet e das redes sociais

(xiv) Alguns aprovam e outros desaprovam essa importante invenção [referindo-se à internet]. Contudo, o modo como essa comunicação acontece entre as pessoas seja por recados, emails ou "tweets" não deveria ser o foco de preocupação dos indivíduos, mas sim as boas consequências que trouxeram ao facilitar a difusão de informação entre as pessoas. Viva a Internet! Viva as Redes Sociais! (red.2)

(xv) Está longe de ocorrer um empobrecimento nos meios de comunicação, o que está acontecendo é até o contrário. As pessoas estão arrumando um jeito de estar cada vez mais pró ximas mantendo contato a todo momento mesmo que em dez, vinte palavras ou nos modernos 140 caracteres. (red. 31)

(b) A produtividade da palavra internamente persuasiva consiste precisamente em que ela desperta nosso pensamento e nossa nova palavra autônoma, em que ela organiza do interior as massas de nossas palavras, em vez de permanecer numa situação de isolamento e imutabilidade (BAKHTIN, 1993, p. 145)

(xvi) (...) As redes sociais revolucionaram o modo como as pes soas comunicam entre si (....) Além disso, a internet - juntamente com as redes sociais - conseguiu acelerar ainda mais a distribuição de informações ao redor do mundo. Por exemplo, se algo acontecesse em qualquer lugar do país, e os donos desse estabelecimento abafassem a informação, certamente alguém - não os donos - poderia dispersar essa informação ape nas com 140 caracteres. (red.2)

(xviii) A globalização tem muitos críticos e boa parte deles, os mesmos que dizem que a linguagem vem se deteriorando criticam talvez por não perceber de que se trata de uma evolução 
e não o contrário. (...) Portanto, nossa comunicação evolui como sempre evoluiu apesar de alguns saudosistas quererem ficar presos ao passado, felizmente nossa linguagem é como um organismo vivo e segue sua evolução sem tomar conhecimento dessas pessoas. (red.20)

\section{Aspectos interpretáveis e considerações}

0 artigo procurou recolocar questões já exploradas para buscar compreender as práticas de letramento que se evidenciam por meio da leitura da palavra e do mundo realizada pelos candidatos no ato da escrita no evento vestibular. Todo uso da língua, diz Stubbs (2002, p. 147), “está vinculado ao contexto, mas existem graus. E a capacidade de focalizar criticamente a língua em si permite a distinção entre o que as pessoas querem dizer e o que as palavras significam."

Ainda que se pretenda olhar para as redações de modo a entender que há um esforço real dos candidatos quando recortam e reproduzem as palavras alheias "que se tornarão, de forma elaborada, palavras próprias, pela integração e autonomia que ganharão no discurso daquele que delas se apropriou" (GOULART, 2007, p.98), o tom predominantemente monolítico dos argumentos, a restrição da linguagem em termos dos usos linguísticos, a redundância temática e estilística, as práticas de linguagem mais do que propriamente as habilidades fazem-nos pensar nos desafios que a escola precisa enfrentar no sentido de transformar modos de elaborar a escrita que possam contribuir para que os alunos construam conhecimentos "renovados", "ressignificados" por meio da língua escrita "especializada".

Diante do já conhecido no campo da experiência e do cotidiano, uma vez que o tema remete às experiências do dia-a-dia, às práticas sociais e interacionais vividas pelos candidatos, por que há um modo de dizer aprisionado à palavra de autoridade? Os candidatos calam subliminarmente o conhecimento prévio e de mundo com o qual lidam diariamente para reelaborarem formas de conhecimento mais elaboradas? As ressignificações daquilo que é familiar, no caso, ecoam a epistemologia escolar, mas, é possível afirmar que os usos cotidianos da língua foram transformados em usos especializados (discursos secundários) em direção a uma compreensão mais ampla - em termos de inserção e participação social - das formas e funções da língua?

Para autores como Lacasa (1999, p. 120), os estudantes "não reproduzem apenas um conjunto de conhecimentos, mas também o 
que se valoriza no contexto escolar" - práticas de letramento escolar em nosso entendimento. Na epistemologia escolar, calcada no "nível de compreensão do conhecimento alcançado em um determinado domínio" (RODRIG0, 1999, 222), os candidatos mostram o que aprenderam sobre os usos escolares da escrita e sobre as formas de argumentar e elaborar o conhecimento num processo de mediação didática. Aprender uma disciplina escolar equivale a aprender a linguagem dessa disciplina, diz Stubbs (2002), o que implica aprender a língua dos professores, dos livros didáticos e dos próprios alunos, ou seja, a língua que circula na esfera escolar, o que explica a reelaboração do conhecimento cotidiano em escolar.

Em perspectiva semelhante, Smolka (2012, p.45) destaca que professores e alunos assumem suas tarefas de acordo com as representações sociais, que incluem formações imaginárias e senso comum. As representações sociais, como forma de aprendizagem situada, podem explicar o porquê de os candidatos escreverem para serem compreendidos pelo outro, como forma de agir sobre o outro na intenção de alcançarem as expectativas do contexto (evento de letramento). Nesse sentido, os candidatos constroem suas argumentações: "0 trabalho do sujeito com a linguagem se expõe com base na própria relação com o outro; seu texto, mais do que trazer à tona o seu querer dizer, revela o esforço que faz para se fazer compreender pelo outro" (OLIVEIRA, 2013, p. 193).

No esforço de ser compreendido pelo outro, há uma dupla orientação: a expressão de estereótipos linguísticos x o conhecimento especializado. Para Stubbs (2002, p. 145), “os estereótipos corriqueiros sobre a língua subestimam grosseiramente as complexidades envolvidas"; o conhecimento especializado reveste-se de lugares-comuns e concepções encontradas na mídia e em visões típicas do conhecimento cotidiano. Por sua vez, esse conhecimento não é espelho da realidade, mas "uma forma de entender o mundo que está em interação contínua com as demais formas de conhecimento e que, portanto, é diversa e está sujeita a evolução" (GARCÍA, 1999, p. 97).

Como saber implícito, os textos revelam (refratam) paradoxalmente aquilo que os sujeitos entendem ser o modo de dizer esperado pela banca (evento de letramento) ou o modo como aprenderam a usar a língua escrita em textos argumentativos formais (práticas de letramento).

Em síntese, a análise aponta para algumas direções, aparentemente contraditórias, mas complementares, considerando-se que todo 
uso da língua está ligado ao contexto:

(i) a palavra reportada, seja a palavra de autoridade, seja a palavra internamente persuasiva, é dialógica;

(ii) o ajuste ou a aderência ao evento de letramento estimula a produção das práticas de letramento escolar;

(iii) redações que reproduzem a palavra de autoridade reforçam o imaginário sobre a escrita, ou seja, as convenções sociais sobre os usos institucionais da escrita;

(iv) redações em que a palavra de autoridade está mais enfraquecida mostram como é possível ressignificar os usos da língua e do conhecimento especializado.

(v) as práticas de letramento escolar ainda reforçam o modelo autônomo de letramento;

(vi) as práticas de letramento escolar, no entanto, também mostram conflitos, tensões, modos de dizer e ver a realidade, pelas quais é possível vislumbrar trajetórias mais subjetivas sem medo da discordância ("Viva a internet! Viva as redes sociais!"), sem medo da polêmica ("As redes sociais revolucionaram o modo como as pessoas comunicam entre si (....) Além disso, a internet - juntamente com as redes sociais - conseguiu acelerar ainda mais a distribuição de informações ao redor do mundo.”).

Na distinção entre o que as pessoas querem dizer e o que as palavras significam é que reside o $\mathrm{X}$ da questão. 0 que as pessoas querem dizer se expressa no esforço de adequação às práticas e ao evento de letramento em questão, o que mostra o quanto elas sabem em termos de letramento escolar (no sentido de sua pedagogização) e pouco (pois oculto ou dissimulado?) a respeito de outras práticas letradas. 0 que as palavras significam manifesta-se por meio de uma escrita protocolar uma espécie de "produto de valor impessoal de mercado" (pretendendo-se adequados ao evento de letramento) e menos a processos que refletem um trabalho de "subjetividades diferentemente situadas" (SINHA, 1999, p.).

Esses resultados devem-se à cristalização e à gramaticalização de usos linguísticos submetidos às injunções sociais que levam à prevalência de certos modos de orientação em relação à palavra outra - segundo Voloshinov e Bakhtin (2011). Tais modos de orientação à palavra outra se tornam “"gramaticais' numa certa língua, sobressaem-se em relação a seus modelos sintáticos e determinam a percepção e a transmissão da palavra outra por parte dos falantes” (PONZIO, 2011, p.38). 
0 que as pessoas querem dizer e o que as palavras significam é que há muito o que fazer ainda e que todos nós, professores, somos corresponsáveis pela permanência e/ou mudança daquilo que julgamos ser o mais importante para nossos alunos. Talvez tenhamos que definitivamente entender (para agir sobre) que o universo escolar integra vários saberes, várias vozes e realidades que se articulam, que dialogam entre si com fronteiras menos nítidas das que julgamos perceber. E que as práticas de letramento escolar em seu modelo pedagogizado ocultam outras práticas sociais de letramento que, no caso dos autores desses textos, parecem não estar associadas à restrição de acesso às mesmas (conforme o questionário, a maioria dos candidatos é pertencente à classe média), mas, provavelmente, à sua apropriação, internalização, às condições subjetivas para fazê-lo, etc..

As práticas de letramento internalizadas mostram, na superfície textual, a dificuldade que os candidatos têm de elaborar gêneros secundários do tipo argumentativo (considerando-se o total das redações). Também falam do receio de se expressarem fora dos modelos aprendidos na escola, de se expandirem em termos da utilização de outras práticas de letramento.

Para Venturim (2013):

(...) é possivel haver uma tentativa constante de apropriação do discurso apresentado na prova, numa atribuição de expressiva credibilidade aos pontos de vistas dos autores da coletânea e textos das outras seções. 0 despontamento dessa atitude pode ser visto como perpetuação das relações produzidas na esfera escolar, que condicionam o comportamento diante de uma avaliação. Muitos estudantes acostumam-se a tomar como verdade tudo o que é respeitado institucionalmente, sem considerar as condições políticas e sociais que lhe cederam tal estatuto.

Concluindo com as palavras de Goulart (2011, p. 150):

A escola é o lugar de transformação de conhecimentos pelos novos significados que passam a recobrir o que já se sabia e pelas novas modalidades de saber, logo a escola deve ser um importante lugar de renovação das pessoas que ali estão para aprender. 


\section{ABSTRACT}

The aim of this paper is to pose a reflection on explicit or underlying literacy practices in a literacy event such as the Brazilian university entrance exams (vestibular) using, as an object of study, the essays written during that event. We aim to understand the educated writing culture, or Brazilian literacy, in its very extreme, that is, the end of High School, based on Bakhtin's theory of enunciation. Despite pedagogical measures focused on elaborate (argumentative) writing in view of college assessment exams and ENEM (National High School Exam), we know how unsatisfactory its results still are, in terms of the school literacy practices, which still remains to be sufficiently reflected on. It is also worth highlighting that we understand writing (school writing) more as a set of social practices than as a set of skills alone. KEYWORDS: literacy practice - literacy event- written language.

\section{REFERÊNCIAS}

BAKHTIN, Mikhail. Os gêneros do discurso. In: Estética da Criação Verbal. Tradução: Paulo Bezerra. 4.ed. São Paulo: Martins Fontes, 2003.

. Questões de literatura e de estética. A teoria do romance. São Paulo: Hucitec / UNESP, 1993.

BARTON, D., HAMILTON, M. Literacy practices. In: BARTON, D. HAMILTON, M. IVANIC, R. (eds). Situated literacies: reading and writing in context. London, New York: Routledge, 2000. p. 7-15.

CORRÊA, M.L. G. O modo heterogêneo de constituição da escrita. 1.ed. São Paulo: Martins Fontes, 2004.

GARCÍA, E. A natureza do conhecimento escolar: transição do cotidiano para o científico ou do simples para o complexo? In: RODRIG0, M.J., ARNAY, J. (Orgs.). Conhecimento cotidiano, escolar e científico: representação e mudança. São Paulo: Ática, 1999, p. 75-102.

GEE, J.P. Social Linguistics and Literacies: Ideology in Discourses. New York, Routledge, 2008 [1990].

GOULART, C. Enunciar é argumentar: analisando um episódio de uma aula de História com base em Bakhtin. Pro-Posições, v. 18, n. 3, set./dez. 2007. 
LACASA, P. Construir conhecimentos: um salto entre o científico e o cotidiano? In: : RODRIGO, M.J., ARNAY, J. (orgs.). Conhecimento cotidiano, escolar e científico: representação e mudança. São Paulo: Ática, 1999, p. 103134.

. Alfabetização, discurso científico e argumentação. In: LEITÃo, S., LEITÃo, S., DAMIANOVIC, M.C. (Orgs.). Argumentação na escola: o conhecimento em construção. São Paulo: Pontes, 2011. p.129-152.

. 0 conceito de letramento em questão: por uma perspectiva discursiva da alfabetização. Bakhtiniana, São Paulo, v.9, n.2, p. 35-51, ago./dez., 9 (2): 35-51, 2014.

KALMAN, J. El acceso a la cultura escrita: la participación social y la apropriación de conocimientos em eventos cotidianos de lectura y escritura. Revista Mexicana de Investigación Educativa, v.8, n. 17, p. 37-66, enero/ abril. 2003.

LACASA, P. Construir conhecimentos: um salto entre o científico e o cotidiano? In: RODRIGO, M.J., ARNAY, J. (Orgs.). Conhecimento cotidiano, escolar e científico: representação e mudança. São Paulo: Ática, 1999. p.103-134. LOPES, A. R. C. Conhecimento escolar: ciência e cotidiano. Rio de Janeiro: EDUERJ, 1999.

LOPES, A. C. Políticas de integração curricular. Rio de Janeiro: EDUERJ, 2008.

MATENCIO, M. de L. Letramento na formação do professor. Integração a práticas discursivas acadêmicas e construção da identidade profissional. In: CORRÊA, M. L. G.; BOCH, F. (Orgs.). Ensino de língua: representação e letramento. Campinas, São Paulo: Mercado de Letras, 2006. p. 93-106.

MODR0, M. V. Gêneros discursivos e escola: reflexões sobre as contribuições dos estudos do letramento para o processo de ensino e aprendizagem de língua materna. In: OSORIO, E. M. R. (Org.). Mikhail Bakhtin e os gêneros do discurso na educação. São Carlos: Pedro \& João Editores, 2011. p. 127140.

OLIVEIRA, L. F. As relações dialógicas na produção de textos de Ensino Médio. In: GOULART, Cecília, WILSON, Victoria (Orgs.). Aprender a escrita; aprender com a escrita. São Paulo: Summus, 2013. p. 165-196.

PONZIO, A. Problemas de sintaxe para uma linguística da escuta. In: VOLOCHÍNOV, Valentin N., BAKHTIN, Mikhail M. Palavra própria e palavra outra na sintaxe da enunciação. São Carlos: Pedro \&t João Editores, 2011. ROCKWELL, E. Os usos escolares da língua escrita. Caderno de pesquisas, São Paulo (52), p.85-95, fev. 1985.

RODRIGO, M. J. Do cenário sociocultural ao construtivismo episódico: uma 
viagem ao conhecimento escolar mediante as teorias implícitas. In: RODRIG0, M.J., ARNAY, J. (Orgs.). Conhecimento cotidiano, escolar e científico: representação e mudança. São Paulo: Ática, 1999. p. 219-238.

SINHA, C. Pessoas situadas: aprender a ser um aprendiz. In: BLISS, J., SÃLJÕ, R., LIGHT, P. (eds.). Learning sites: social and technological resources for learning. Oxford: Pergamon, 1999. p. 32-48.

SMOLKA, A.L.B. A criança na fase inicial da escrita: a alfabetização como processo discursivo. São Paulo: Cortez, 2012.

SOARES, M. In: RIBEIRO, V. M. (Org.). Letramento no Brasil: reflexões a partir do INAF 2001. São Paulo: Global, 2003. p.89-114.

STREET, B. V. What's "new" in New Literacy Studies? Critical approaches to literacy in theory and practice. Disponivel em: http://people.ufpr.br/ clarissa/ pdfs/NewInLiteracy_Street.pdfı. Acesso em: 14 abr.2015.

. Os Novos Estudos do Letramento: histórico e perspectivas. In: MARINHO, M., CARVALHO, G. T. (Orgs.). Cultura escrita e letramento. Belo Horizonte: Editora UFMG, 2010. p.33-53.

. Letramentos sociais: abordagens críticas do letramento no desenvolvimento, na etnografia e na educação. São Paulo: Parábola, 2014 [1995]. STUBBS, M. A língua na educação. In: BAGNO, M., STUBBS, M., GAGNĖ, G. Lingua materna: letramento, variação, ensino. São Paulo: Parábola, 2002, p. $85-162$.

VENTURIM, A. P.S. Saberes e interlocuções na redação do vestibular. Monografia de conclusão de curso. Faculdade de Formação de Professores da UERJ. São Gonçalo, 2013.

VOLOCHÍNOV, V. N., BAKHTIN, M. M. Palavra própria e palavra outra na sintaxe da enunciação. São Carlos: Pedro \& João Editores, 2011.

WILSON, V. Redação de vestibular: um gênero híbrido. Revista Linguagem \& Ensino, Pelotas, v.15, n.1, p.87-112, jan./jun. 2012

WILSON, V. A leitura da palavra alheia e a construção do conhecimento em redações de vestibular. In: WILSON, V., MORAIS, J. (Orgs.). Leitura, escrita e ensino: discutindo a formação de leitores. São Paulo: Summus, 2015. p. 213233.

Recebido em 30 de abril 2015

Aprovado em 10 de maio de 2015 